\title{
Multiple Sklerozlu Gebede Anestezi Yönetimi
}

\section{Management of Anesthesia in a Pregnant with Multiple Sclerosis}

\author{
Yusuf Ziya ÇOLAK ${ }^{1}$, Ferda YAMAN ${ }^{2}$ \\ ${ }^{I}$ Sivas Kangal Devlet Hastanesi Anesteziyoloji ve Reanimasyon Kliniği, SiVAS \\ ${ }^{2}$ Kirlkkale Üniversitesi Tip Fakültesi Anesteziyoloji ve Reanimasyon A. D., KIRIKKALE
}

\begin{abstract}
ÖZET
Multiple skleroz (MS), genetik faktörlerin de önemli oranda rol aldığı çoğunlukla kadın hastaların etkilendiği yaygın olarak gözlenmekte olan santral sinir sisteminin immun-demiyenilizan hastalığıdır. Stress, cerrahi, anestezi, emosyonel sıkıntı, vücut 1S1S1 değişiklikleri MS semptomlarında artmaya ve remisyondaki hastada yeni ataklara yol açabilir. Gebelik döneminde son trimesterda regresyon gösterdiği bununla birlikte gebelikten sonraki 3 ayda atakların belirgin arttı̆g bilinmektedir. Spinal anestezi, olasılıkla lokal anesteziklerin demiyelinizan nöronlara karşı artmış nörotoksik etkilerine bağlı olarak hastalığın postoperatif alevlenmesi neden olur. MS'de nöral dokudaki demiyelinizasyon spinal kordu lokal anesteziklerin histotoksik etkisine daha hassas hale getirir, bu yüzden spinal anestezinin kontrendike olduğunu bildiren yayınlar mevcutken spinal ve epidural anestezinin rölatif kontrendikasyon oluşturduğunu bildiren yayınlar da mevcuttur. Genel anestezi uygulamalarında kas gevşetici ilaçlar dikkatli kullanılmalıdır. Bu olguda elektif koşullarda sezaryen operasyonu planlanmış 26 yaşında MS hastası 38 haftalık nullipar gebe ve anestezik yaklaşımı literatür eşliğinde sunmayı amaçladık. Hastaya ameliyat, anestezi yöntemi ve riskler açıklandıktan sonra genel anestezi uygulamasına karar verildi. Kas gevşeticisiz entübasyon planlanmış olup propofole bağlı şiddetli ve yaygın myoklonik kasılmalar gözlenmiş olan olguda düşük doz kas gevşetici uygulanarak komplikasyonsuz entübasyon gerçekleştirildi. Anestezi idamesi sevofluran beraberinde remifentanil infüzyon ile sağlandı. Hastanın vücut 1s1 monitorizasyonu postoperatif 24 saat boyunca takip edildi. Postoperatif 4 hafta boyunca MS atak benzeri semptomlara rastlanmadi.
\end{abstract}

Anahtar Kelimeler: Multiple sklerozis, anestezi, spinal, Keywords: Multiple sclerosis, anaesthesia, epidural, spinal epidural
Multiple Sclerosis (MS) is the most common immune demyelinating disorder of the central nervous system which predominantly affects females and play a major role which is involved in genetic factors. Stress, surgery, anaesthesia, emotional distress, changes with body temperature may cause an increase syptom of MS and new attacks in a remission period of a patient. In pregnancy period, regression in third trimester besides increasing attacks after delivery in first 3 months is known. Spinal anaesthesia, probably depending on local anaesthetics increased neurotoxic effects on demyelinated neurons causes exacerbation of the disease postoperatively.. While in MS, demylenation in neural tissue makes spinal cord more sensitive histotoxic effects of local anaesthetics, because of this there are some reports noticed that spinal anaesthesia is contraindicated but also there are some reports noticed that spinal and epidural anaesthesia is relative contraindicated. Neuromusculer bloker agents should be used carefully during application of general anaesthesia. We aimed to present anaesthetic approach with literature to a pregnant with MS who was in 38th week of pregnancy, 26 year-old, nullipar planned for ellective cesarian sectio. After description of surgery, anaesthetic management and risks to patient decided to perform general anaesthesia. Intubation was planned without neuromuscular blockade, myoclonic widespread seizures was observed according to propofol, by administering low doses of muscle relaxant, intubation was performed without any complication. Anaesthesia maintaining was achieved with sevoflurane and infusion of remifentanyl. Body temperature was monitored through 24 hours postoperatively. There were not seen any sypmtoms like attacks of MS through 4 weeks postoperatively. 


\section{GIiRIŞ}

Multiple skleroz (MS), genetik faktörlerin de önemli oranda rol aldığı çoğunlukla kadın hastaların etkilendiği yaygın olarak gözlenmekte olan santral sinir sisteminin immun-demiyenilizan hastalığıdır. Multiple skleroz (MS), genetik faktörlerin de önemli oranda rol aldığı çoğunlukla kadın hastaların etkilendiği yaygın olarak gözlenmekte olan santral sinir sisteminin immun-demiyenilizan hastalığıdır (1). MS; beyin ve spinal kordda inflamasyon, demiyelinizasyon ve aksonal hasarla karakterizedir. Aksonları çevreleyen myelinin kaybı, skar dokusu veya plakların oluşumuna neden olur (2). MS, nörolojik disfonksiyonun remisyon ve relapsları ile karakterize bir hastalıktır (3). Perioperatif stres ve anestezi, multiple skleroz atakların alevlenmesine neden olabilen faktörlerdir. Enfeksiyon, duygusal labilite ve yüksek ateş, artmış postoperatif multipl skleroz alevlenme sıklı̆̆ını açıklayabilir. Gebelik döneminde son trimesterda regresyon gösterdiği bununla birlikte gebelikten sonraki 3 ayda atakların belirgin arttığı bilinmektedir (4). Literatürde MS'li gebelerde anestezi uygulamalarında epidural, spinal ve genel anestezi uygulamaları mevcut olup tüm anestezik teknikler MS semptomlarının alevlenmesine neden olabileceği bildirilmiştir (5). Rejyonal anestezi uygulamalarında sempatik bloğa bağlı intravenöz sıvılara ve vazopressör tedaviye dirençli ciddi hipotansiyon gelişebileceği rapor edilmiştir $(6,7)$. Buna karşıt spinal ve epidural anestezinin MS ataklarını alevlendirmediğini bildiren yayınlar da mevcuttur.(8) Anestezi yöntemi ve yönetimi MS'li hastalarda dikkatli seçilmeli ve post-op vücut sıcaklığı takibi ve ağrı takibi önem arzetmektedir.

\section{OLGU}

26 yaşında, nullipar, 38 haftalık gebe sezaryen seksiyo planlanmış 6 saatlik açlık süresi beklenerek ameliyathaneye kabul edildi. Hastaya ameliyat, anestezi yöntemi ve riskler açısından gerekli açıklama yapıldı. Preoperatif değerlendirmede gebelikten 1 y1l önce MS tanısı aldığı ve steroid tedavisinin gebelik dolayısıyla kesildiği öğrenildi. Fizik muayanesinde solunum sesleri normal ve mallampati skoru 1 olan hastanın gebelik sürecinde ataklarının olmadığı öğrenildi. Biyokimyasal kan tetkik sonuçları normal olan hasta ASA 2 olarak değerlendirildi ve kasgevşetici kullanmadan genel anestezi planlandı. Standart monitorizasyona vücut sicaklık monitorizasyonu eklenerek preoksijenizasyon sonrası 2,5 $\mathrm{mg} / \mathrm{kg}$ propofol ile induksiyon uyguland. İndüksiyon sırasında yaygın ve şiddetli myoklonik kasılmaların olması nedeniyle $125 \mathrm{mg}$ tiyopental sodyum ve düşük doz $20 \mathrm{mg}$ rokuronyum ilave edilmek durumunda kalındı. Tiyopental sodyum ile myoklonik kasılmaları kesildi. Anestezi idamesi sevoflurane \% 1 ve $\% 50 \mathrm{O}_{2}+$ hava ile sağland. Bebek çıkma zamanı 5 dakika olup pediyatri doktorları tarafindan 0. dakika APGAR skoru 8 olarak kayit edildi. Bebek çıktıktan sonra operasyon bitim süresine kadar $0.25 \mu \mathrm{g} / \mathrm{kg} / \mathrm{dk}$ remifentanil infüzyon uygulandı. Operasyon süresince hemodinamik açıdan ve termal açıdan stabil seyreden hastanın postoperatif 24 saat boyunca monitorizasyona devam edilerek 6 saat arayla 1gr parasetamol uygulaması ile ağrı kontrolü sağlandı. Vücut sıcaklığ $36,5^{\circ} \mathrm{C}$ de sabit tutulmaya çalışıldı. Sezaryen sonrası 4 hafta boyunca atak gözlenmedi. 


\section{TARTIŞMA}

Cerrahi, anestezi, emosyonel s1kınt1, vücut 1sis1 değişiklikleri MS semptomlarında artmaya veya remisyondaki hastalarda yeni ataklara yol açabilir. Tüm anestetezik yöntemler MS semptomlarının alevlenmesine neden olabilir. Literatürde obstetrik hastalarda epidural ve spinal anestezi uygulanan hastalarda MS klinik özellikleri ve anestezi yöntemi arasındaki ilişkiyi araştıran retrospektif çalışmalar ve olgu sunumları mevcuttur $(8,9)$. Ellen ve arkadaşları yapmış oldukları retrospektif çalışmada hastalık süresi ve güçsüzlük (Expanded Disability Status Scale (EDSS) skoru ile uygulanan anestezi yöntemi arasında ilişki olmadığını ayrıca hastalık süresinin uzun olmasıyla epidural anestezi uygulamasının spinal anesteziye göre daha fazla olduğunu belirtmektedirler ve ileri çalışmaların yapılması gerektiğini vurgulamaktadırlar (8). Spinal ve epidural anestezinin ayrı ayrı değerlendirilmesi gerekmektedir çünkü farklı farmokokinetikleri ve endikasyonları olduğu gibi farklı yan etki riskleri mevcuttur. Literatürde MS hastalarında güvenli anestezi yöntemi ile ilgili kesin ve net veri olmadığından biz gebelik sürecinde remisyonda olan bu olguda genel anestezinin daha güvenli olabileceğini düşünerek genel anestezi uygulamasını tercih ettik.

Barbosa ve arkadaşları, metilprednizolon ile tedavi edilmiş MS hastası olan bir gebede hiperbarik bupivakain ile spinal anestezi uygulamışlar ve semptomlarında artış olmadığını bildirmişlerdir (9). Buna rağmen spinal anestezinin rölatif kontrendikasyon olarak düşünülmesi gerekmektedir çünkü lokal anesteziklerin demiyelinize nöronlara toksik etkileri MS ataklarını tetikleyebilir. Buna ek olarak, iğne'ye bağlı travma ve stres, nöroaksiyel anestezi sırasında tekniğin zorluğu ve hipotansiyon relapsa neden olabilir (5). Epidural anestezi, lokal anesteziğin düşük dozlarda intratekal aralığa penetrasyonu ve hipotansiyon prevelansının düşük olmasından dolayı spinal anesteziye göre daha güvenli kabul edilebilir (5).
MS hastalarında genel anestezi uygulamasının da avantaj ve dezavantajları vardır. İnhalasyon anestezikleri ile başarılı bir şekilde indüksiyon ve idamenin sağlandığını bildiren çalışmalar mevcuttur (1). Bizim vakamızda hastamızın gebe olması daha titizlikle yaklaşmamızı gerektirdiğinden sadece idamede sevofluran ile inhalasyon anestezik ajanı kullanıldı. Kono Y ve arkadaşları acil laparatomi nedeniyle MS hastasının genel anestezi uygulamasında hiç kas gevşetici kullanmadan propofol, fentanil ile indüksiyon sağlamışlar, idamede ise sevofluran, $\mathrm{O}_{2}$, hava kullandıklarını ve postoperatif dönemde MS semptomlarında alevlenme olmadığını belirtmişlerdir (10). Biz bu olguda kasgevşetici kullanmamayı planlamıştık ancak yaygın ve şiddetli miyoklonik kasılmaları olmasından dolayı düşük doz rokuronyum uygulamak zorunda kaldık. Hastanın ekstübasyon süresinde herhangi bir uzama olmadı.

Lee KH ve arkadaşları da 2 yıllık MS öyküsü olan acil laparotomi nedeniyle genel anestezi uyguladıkları hastada propofol ve remifentanil ile indüksiyon ve sevofluran ve remifentanil ile de idameyi sağladıklarını ve postoperatif dönemde semptomlarda artış olmadığını bildirmişler ve sevofluranın MS'li hastalarda güvenli olduğunu vurgulamışlardır (11). Bu vaka ile uyumlu olarak biz de olgumuzda bebek çıktıktan sonraki dönemde remifentanil ve sevofluran ile idameyi sağladık.

MS hastalarının anestezi yönetiminde vücut sıcaklığındaki artış demiyelinize aksonlarda iletim bloklarına yol açabileceği bilinmektedir (12). Bu hastada vücut s1caklık monitorizasyonu uygulanarak hipotermiden kaçınıldı, avantajımız cerrahi sürenin kısa olmasiyd1.

Sonuç olarak, uygulanan bu genel anestezi yönteminin literatür ile uyumlu olarak güvenli, derin, stabil bir anestezi sağlayabileceği düşünüldü. 


\section{KAYNAKLAR}

1. Dorotta IR, Schubert A. Multiple sclerosis and anesthetic implications. Curr Opin Anaesthesiol. 2002; 15(3): 365-70.

2. Stoelting RK, Dierdorf SE. Anesthesia and CoExisting Disease. 3rd ed. New York, NY: Churchill Livingstone, 2002: 268-9.

3. Albin MS. Neurologic Syndromes and Disorders with Their Anesthetic Implications. Wonsiewics MJ, Melvin S. 1st edition. Textbook of neuroanesthesia with neurosurgical and neuroscience perspectives. The McGraw-Hill Companies Inc, 1997: 421-6.

4. Coyle PK. Multiple sclerosis in pregnancy. Continuum (Minneap Minn). 2014; 20(1 Neurology of Pregnancy): 42-59.

5. Vercauteren M, Heytens L. Anaesthetic considerations for patients with a pre-existing neurological deficit: are neuroaxial techniques safe? Acta Anaesthesiol Scand. 2007; 51(7): 831-8.

6. Kattula A, Kranner P, Arndt G. Regional anesthesia in the presence of neurologic disease. Finucane BT. Complications of Regional Anesthesia. Churchill Livingstone, 1999: 294-6.
7. Kytta J, Rosenberg PH. Anesthesia for patients with multiple sclerosis. Ann Chir Gynaecol. 1984; 73: 299-303.

8. Ellen Lu, Yinshan Zhao, Leannne Dahlgren. Obstetrical epidural and spinal anesthesi in multiple sclerosis. J Neurol. 2013; 260: 2620-28.

9. Barbosa FT, Bernardo RC, Cunha RM. Subarachnoid anesthesia for cesarian section in a patient with multiple sclerosis: case report. Rev Bras Anesthesiol. 2007; 57(3): 301-16.

10. Kono Y, Ueda N, Kano T. Anesthetic considerations for a patient with multiple sclerosis. Masui. 2005; 54(8): 906-8.

11. LeeKH, Park JS, Lee SI,Kim KT. Anesthetic management of the emergency laparatomy for a patient with multiple sclerosis-A case report. Korean J Anesthesiol. 2010; 59(5): 359-62.

12. Guthrie TC, Nelson DA. Influence of temperature changes on multiple sclerosis: critical review of mechanisms and research potential. J Neurol Sci. 1995; 129(1): 1-8. 